\title{
Prevalence of Suicide Ideation and its Relationship with Depression among Transgender Population
}

\author{
Rao Azeem1, Usama Bin Zubair², Aneza Jalil3, Asif Kamal4, Asad Nizami1 and Fareed Minhas ${ }^{5}$
}

\begin{abstract}
Objective: To record the prevalence of suicidal ideation in the transgender population and assess the relationship of depression with the suicidal ideation.

Study Design: Cross-sectional study.

Methodology: The study group comprised of 156 transgender people of Rawalpindi and Islamabad. Suicidal ideation was assessed by the scale for suicide ideation (SSI). Hamilton rating scale for depression (HAM-D) was used to look for the presence and severity of depression among the target population. Relationship of the age, smoking, family income, illicit substance use, and depression was studied with the presence of suicidal intent among these transgender population of twin cities.

Results: One hundred and fifty-six transgender people were included in this study. Mean age of the study participants was $39.26 \pm 4.28$ years. Out of them, $89(57.1 \%)$ had no suicidal ideations, while $67(42.9 \%)$ had suicidal ideation. Fifty-seven $(36.5 \%)$ did not showed depression, while $99(63.5 \%)$ had depression on HAM-D. With binary logistic regression, depression and illicit substance were found to be significantly related to the presence of suicidal ideations in the target population $(p<0.05)$.

Conclusion: A high prevalence of suicidal ideation among the transgender population of twin cities was found in this study. Depression, illicit substance use, and other mental health illnesses should be screened routinely on this high risk population for early recognition and treatment.
\end{abstract}

Key Words: Depression, Suicide intent, Transgenders.

\section{INTRODUCTION}

Depression is one of the most frequently diagnosed psychiatric illnesses, which remains a big cause of mortality and morbidity among all groups of population. ${ }^{1}$ Things are not different in our part of the world as depression remains a common mental health illness in our population. 2 If untreated, it may lead to serious consequences including severe depression with psychotic illness, physical problems and even suicide. ${ }^{3-5}$

Transgender is a broad term which includes the people with all types of gender identity disorder. ICD-11 coins a new term for this group of people, i.e. gender incongruence. In United States of America, 390/100,000 individuals are believed to be transgenders. ${ }^{6}$ Census of 2017 has shown that more than 10,000 transgender

1 Department of Psychiatry, Benazir Bhutto Hospital, Rawalpindi, Pakistan

2 Department of Psychiatry / Medicine ${ }^{3}$, Pakistan Institute of Medical Sciences (PIMS), Islamabad, Pakistan

4 Department of Psychiatry, Gajju Khan Medical College, Swabi, KPK, Pakistan

5 Department of Mental Health, WHO Collaborating Centre, Institute of Psychiatry, Rawalpindi, Pakistan

Correspondence: Dr. Usama Bin Zubair, Department of Psychiatry, Pakistan Institute of Medical Sciences (PIMS) / SZABMU, Islamabad, Pakistan

E-mail:drusamabinzubair@yahoo.com

Received: August 15, 2018; Accepted: October 25, 2018 subjects exist in Pakistan. They suffer from various health issues including the HIV, drug dependence, and various mental health problems. 7,8

Previous research highlights the presence of depression and suicide ideation among the transgender population. Depression, suicide and other mental health indices are very high among the transgender population as compared to controls even in a developed country like USA. ${ }^{9}$ Another study showed suicide attempt rate as $32-50 \%$ among the transgender population of our neighboring country India. This was also coupled with increased rate of depression among the target population. 10 Oswalt et al. concluded in a large study that all mental health illnesses including schizophrenia are found more among the transgender as compared to heterosexual controls. ${ }^{11}$ Depression and suicidal ideation, if remain unaddressed for long, may result in poor life quality and even leading to death. 12

Suicidality and depression have some common biological pathways, which explain one of the bases of their comorbidity. Role of genetics, alteration in the hypothalamic-pituitary-adrenal (HPA) axis, dysregulation of serotonin metabolism and receptors and neuroimmunological basis are some of the factors which contribute in development of both depression and suicidality. ${ }^{13}$ In addition to the biological factors, depression also leads to suicidal ideation and suicidality by psychological and social pathways. ${ }^{14}$ Ideas of self harm are also part of diagnostic criteria for depression in ICD-11. 
Social exclusion and other religious and socio-cultural factors have stigmatized the transgenders in our country. ${ }^{15,16}$ They have been facing difficulties in disclosing their identities at workplace and mostly forced to work as sex-workers or beggars. ${ }^{15}$ This predisposes them to various physical and mental health disorders. A study has been done to look for prevalence of HIV among this group in recent past in our country, 17 but no study has yet been published on their mental health status; so this study was planned with the rationale to determine the prevalence and correlation of suicidal ideation among the transgender population of some parts of the twin cities.

\section{METHODOLOGY}

After ethical approval from concerned Ethical Review Committee and written consent from all potential participants, this cross-sectional study was planned from January to June 2016 in the parts of twin cities of Rawalpindi and Islamabad. Non-probability consecutive sampling technique was used. Sample size was calculated by using the WHO sample size calculator. All the transgenders available at Chandni Chowk and F-9 Markaz in the given dates were included in the study. Exclusion criteria were the transgenders less than 18 years of age or with a past or current history of any chronic physical illness (DM, IHD, HTN, RA or other diseases of chronic nature) or those who underwent medical or surgical treatment for gender dysphoria. Transgenders who were already diagnosed cases of depression or any other psychiatric illnesses, were also excluded. Participants who could not read or perform the questionnaires were also not included in the study.

Transgender is a broad term which includes all the individuals who identify themselves as being or living outside the socially defined roles of masculinity or feminity. ${ }^{6}$ Hamilton rating scale for depression (HAM-D) is a 17 -item clinician rated, standardized and timetested scale to look for the presence and severity of depression. Cut off score used in this study was 7 . Validated Urdu translation was used to avoid the bias. ${ }^{18}$ Scale for suicidal ideation (SSI) is a 19-item clinician rated scale with good internal consistency and valid Urdu translation. Each item is scored from 0-2 with a maximum score of 38. Cut off score of 6 or more was used as that was used in few previous studies, too. 19,20

Ethical Review Committee of the Institution approved this study. Transgenders available at Chandni Chowk, Rawalpindi and F-9 Markaz, Islamabad fulfilling the abovementioned inclusion and exclusion criteria were included in the study after written informed consent. All patients underwent a detailed history taking and systemic examination to rule out the confounding variables like chronic illnesses. HAM-D and scale for suicide ideation were administered to the transgenders by the clinicians. They were asked to answer the questions according to their condition in last two weeks. Sociodemographic variables were collected on a proforma specially designed for this study.

Risk factors and the distribution of transgenders with the suicide ideation were described by using the descriptive statistics. Samples were classed on the basis of presence or absence of significant suicide ideation. Age, smoking, family income, illicit substance use and depression were the variables included in the study. Categorical variables were expressed as frequencies along with the percentages. Chi-square and Fisher exact tests were applied at the first step. Binary logistic regression analysis was done to evaluate factors related to the presence of suicide ideation. All statistical analyses were performed using Statistics Package for Social Sciences version 24.0. Differences between groups were considered significant, if $p$-values were less than or equal to 0.05 .

Table I: General characteristics of the study participants.

\begin{tabular}{|c|c|c|c|c|c|}
\hline \multirow[t]{2}{*}{ Socio-demographic factors } & \multicolumn{2}{|c|}{ No suicide ideation (SSI score <6) } & \multicolumn{2}{|c|}{ Suicide ideation (SSI score >6) } & \multirow[t]{3}{*}{$p$-value } \\
\hline & $\mathrm{N}$ & $\%$ & $\mathrm{~N}$ & $\%$ & \\
\hline Total & 89 & 57.1 & 67 & 42.9 & \\
\hline \multicolumn{6}{|l|}{ Age } \\
\hline$<50$ & 41 & $46.1 \%$ & 23 & $34.3 \%$ & 0.188 \\
\hline 50 or more & 48 & $53.9 \%$ & 44 & $65.7 \%$ & \\
\hline \multicolumn{6}{|l|}{ Family income } \\
\hline More than or equal to outgoing & 81 & $91.1 \%$ & 61 & $91.1 \%$ & 1.000 \\
\hline Less than outgoing & 08 & $9.9 \%$ & 06 & $9.9 \%$ & \\
\hline \multicolumn{6}{|l|}{ Smoking } \\
\hline No & 42 & $47.2 \%$ & 22 & $32.8 \%$ & 0.100 \\
\hline Yes & 47 & $52.8 \%$ & 45 & $67.2 \%$ & \\
\hline \multicolumn{6}{|l|}{ Illicit substance use } \\
\hline No & 76 & $85.3 \%$ & 43 & $64.2 \%$ & 0.002 \\
\hline Yes & 13 & $14.7 \%$ & 24 & $35.8 \%$ & \\
\hline \multicolumn{6}{|l|}{ Depression } \\
\hline No & 43 & $48.3 \%$ & 14 & $20.9 \%$ & $<0.001$ \\
\hline Yes & 46 & $51.7 \%$ & 53 & $79.1 \%$ & \\
\hline
\end{tabular}


Table II: The correlated factors relating to presence of suicide ideation among the transgenders of twin cities: the binary logistic regression

\begin{tabular}{|c|c|c|c|c|}
\hline & \multirow[t]{2}{*}{ p-value } & \multirow[t]{2}{*}{ Odds ratio } & \multicolumn{2}{|c|}{ Confidence interval } \\
\hline & & & Lower & Upper \\
\hline Age (ref. is $<50$ years) & 0.125 & 0.556 & 0.263 & 1.177 \\
\hline Illicit substance use (reference is no use) & 0.001 & 4.321 & 1.823 & 10.241 \\
\hline Smoking (ref. is no smoking) & 0.165 & 1.697 & 0.804 & 3.580 \\
\hline Family income (ref. is more than or equal to outgoing) & 0.767 & 1.206 & 0.350 & 4.152 \\
\hline Depression (ref. is no depression) & 0.003 & 3.206 & 1.482 & 6.936 \\
\hline
\end{tabular}

\section{RESULTS}

One hundred and seventy-five transgenders were initially approached to participate in the study. Two $(1.1 \%)$ refused participation, $16(9.1 \%)$ did not qualify participation due to exclusion criteria, 8 (4.6\%) gave history of medical or surgical treatment for gender dysphoria, 4 (2.3\%) had diabetes mellitus (DM), 2 (1.1\%) had hypertension (HTN), $1(0.6 \%)$ had previous episodes of mood disorder, and $1(0.6 \%)$ was mentally retarded). After being consented, an additional $1(0.6 \%)$ did not provide complete data at baseline, leaving 156 participants who underwent the questionnaire administration. Mean age of the study participants was $39.26 \pm 4$.28. Out of these, $89(57.1 \%)$ had no suicidal ideations, while 67 $(42.9 \%)$ had significant suicidal ideation. Fifty-seven (36.5\%) did not showed depression, while 99 (63.5\%) had depression on HAM-D. Table I shows the general characteristics of the patients. Table II shows that the depression and illicit substance use were strongly associated with the presence of suicide ideation among the transgenders, when regression analysis was done.

\section{DISCUSSION}

To the authors' knowledge, this is the first ever study of its kind in our country on people with problems of gender identity and congruence. The study is an attempt to record presence of suicidal ideations among the people which have been stigmatized by the society for long. Most common psychiatric illness in Pakistan is depression, according to a recent study with a large sample size. ${ }^{21}$ Using the standard psychometric tools, we observed that presence of depression and suicidal ideation is far greater among the transgenders as compared to population without problems of gender identity and congruence. Though, this is in accordance with the studies done on transgenders in other parts of the world.8,9 Important reasons for suicidal ideation among these people may be social injustice, stigma in society, lack of jobs and educational oppurtunities. ${ }^{16}$ Stress, anxiety, depression or other psychological problems are positively linked with suicidal ideation and completed suicide in various studies done in the past.6,9 All these issues have been faced by transgenders in excess to the population without gender related dilemmas. Therefore, prone them towards the thoughts of harming themselves to an extent that their life ends. Slightly more prevalence of mental health indices in this study as compared to other similar studies in the West or developing countries may be either due to overall compromised socio-economic environment or extreme religo-cultural stigmatization which is less prevalent in other parts of the world regarding people with gender incongruence. 16

Increasing age has been a consistent correlate with presence of suicidal ideation among the transgenders in various studies done in the past.22,23 The results in this study were different and age was not related to presence of suicide ideation in the target population. Reason might be that transgender community usually lives separately from the routine population; and as the member gets older, he is appointed as head of group of transgender people who work and earn under him. Therefore, he is exempted from routine duties but also remains productive in administrative chores.

Monthly income was not found to be significantly correlated with the presence of suicidal ideation in the target population which was in contrast to the existing literature worldwide. 22 Overall status of income was satisfactory in most of the study participants as some of them used to work as sex workers and beggars in posh areas and used to make both ends meat easily. However, studies regarding work satisfaction may generate interesting results on this subject.

Depression was a consistent correlate with suicidal ideation in this study. Various studies done on people with and without gender identity problems have confirmed this association. 22,23 This association can be due to common biological factors or social stigma linked with transgenders in our setup. All over the world, people with gender identity disorders have been at greater risk of physical and mental ailments including depression and suicide as compared to rest of the population. The greater severity in our target population may be due to the complex religo-cultural scenario, which lays emphasis on the punishment of the deviant behaviors associated with gender incongruence. ${ }^{16}$ Further studies, especially qualitative studies designed to explore this phenomenon, may be helpful in determining the exact causes of this association.

Illicit substance use included cannabis, opiates, benzodiazepines, and organic solvents. Their use was strongly related with the presence of suicidal ideations in the present study. Past literature also supports our findings. ${ }^{23}$ Illicit substance use may be a maladaptive 
coping strategy for the existing stressors, which may further add to the mental health problems and lead to the suicidal thoughts. HIV and other physical illnesses are also more common among the people who use the illicit substance.

This study has few limitations as well. The findings cannot be generalized as the study population was not selected from a randomized sample of all the transgender population of our country. Instead, a small portion was targeted from two cities of Pakistan. Another limitation is the chance that the subjects may under or over report the symptamatology on self administered questionnaires like HAM-D and scale for suicide intent. We suggest further studies on broader-based and more representative sample size using locally developed and standardized psychometric tools on the subject in order to look for the mental health problems and their determinants among this high risk population.

\section{CONCLUSION}

This study showed a high prevalence of suicidal ideation among the transgender population of twin cities. Routine screening for depression, illicit substance use, and other mental health illnesses should be performed on this high risk population for early recognition and treatment.

Disclosure: This is a dissertation-based article.

\section{REFERENCES}

1. Wang J, Wu X, Lai W, Long E, Zhang X, Li W, et al. Prevalence of depression and depressive symptoms among outpatients: A systematic review and meta-analysis. BMJ Open 2017; 7: e017173.

2. Godil A, Mallick MSA, Adam AM, Haq A, Khetpal A, Afzal R, et al. Prevalence and severity of depression in a Pakistani population with at least one major chronic disease. J Clin Diagn Res 2017; 11:0C05-10

3. Li H, Luo X, Ke X, Dai Q, Zheng W, Zhang C, et al. Major depressive disorder and suicide risk among adult outpatients at several general hospitals in a Chinese Han population. PLoS One 2017; 12:e0186143.

4. Clarke JL, Skoufalos A, Medalia A, Fendrick AM. Improving health outcomes for patients with depression: A population health imperative. Report on an expert panel meeting. Popul Health Manag 2016; 19(Suppl 2):S1-S12.

5. Heslin M, Desai R, Lappin JM, Donoghue K, Lomas B, Reininghaus $\mathrm{U}$, et al. Biological and psychosocial risk factors for psychotic major depression. Soc Psychiatry Psychiatr Epidemiol 2016; 51:233-45.

6. Blosnich JR, Brown GR, Shipherd JC, Kauth M, Piegari RI, Bossarte RM. Prevalence of gender identity disorder and suicide risk among transgender veterans utilizing veterans health administration care. Am J Public Health 2013; 103: e27-32.
7. Ebrahim, Zofeen T. Don't we count? Transgender Pakistanis feel sidelined by census. Thomson Reuters. Thomson Reuters Foundation. Retrieved 2018-05-02.

8. Perez-Brumer AG, Oldenburg CE, Reisner SL, Clark JL, Parker RG. Towards 'reflexive epidemiology': conflation of cisgender male and transgender women sex workers and implications for global understandings of HIV prevalence. Glob Public Health 2016; 11:849-65.

9. Brown GR, Jones KT. Mental health and medical health disparities in 5,135 transgender veterans receiving healthcare in the veterans health administration: A case-control study. LGBT Health 2016; 3:122-31.

10. Virupaksha HG, Muralidhar D, Ramakrishna J. Suicide and suicidal behavior among transgender persons. Indian $J$ Psychol Med 2016; 38:505-9

11. Oswalt SB, Lederer AM. Beyond depression and suicide: The mental health of transgender college students. Soc Sci 2017; 6

12. De Medeiros Alves V, de Lima Francisco LCF, Belo FMP, de-Melo-Neto VL, Barros VG, Nardi AE. Evaluation of the quality of life and risk of suicide. Clinics (Sao Paulo) 2016; 71:135-9.

13. Pandey GN. Biological basis of suicide and suicidal behavior. Bipolar Disord 2013; 15:524-41.

14. Conejero I, Olié E, Calati R, Ducasse D, Courtet P. Psychological pain, depression, and suicide: Recent evidences and future directions. Curr Psychiatry Rep 2018; 20:33.

15. Abdullah MA, Basharat Z, Kamal B, Sattar NY, Hassan ZF, Jan $A D$, et al. Is social exclusion pushing the Pakistani Hijras (Transgenders) towards commercial sex work? A qualitative study. BMC Int Health Hum Rights 2012; 12:32.

16. Saeed A, Mughal U, Farooq S. It's complicated: sociocultural factors and the disclosure decision of transgender individuals in Pakistan. J Homosex 2018; 65:1051-70.

17. Nasrullah M. Concentrated HIV epidemic in Pakistan: An opportunity to prevent generalized epidemic. Int J Prev Med 2012; 3:824-6.

18. Hashmi AM, Naz S, Asif A, Khawaja IS. Urdu translation of the Hamilton rating scale for depression: Results of a validation study. Pak J Med Sci 2016; 32:1479-83.

19. Holi MM, Pelkonen M, Karlsson L, Kiviruusu O, Ruuttu T, Heilä H, et al. Psychometric properties and clinical utility of the scale for suicidal ideation (SSI) in adolescents. BMC Psychiatry 2005; $5: 8$.

20. Sokero TP, Melartin TK, Rytsala HJ, Leskela US, LestelaMielonen PS, Isometsa ET. Suicidal ideation and attempts among psychiatric patients with major depressive disorder. J Clin Psychiatry 2003; 64:1094-1100.

21. Ahmed B, Enam S, lqbal Z, Murtaza G, Bashir S. Depression and anxiety: A snapshot of the situation in Pakistan. Int $\mathrm{J}$ Neurosci 2016; 4:32-6.

22. Yüksel S, Aslantas Ertekin B, Öztürk M, Bikmaz PS, Oglagu Z. A clinically neglected topic: Risk of suicide in transgender individuals. Noro Psikiyatr Ars 2017; 54:28-32.

23. Clements-Nolle K, Marx R, Katz M. Attempted suicide among transgender persons: The influence of gender-based discrimination and victimization. J Homosex 2006; 51:53-69. 